\title{
Traditional drug-discovery model ripe for reform
}

\section{Academic researchers set to play much greater role in pharmaceutical development.}

\section{BY DANIEL CRESSEY}

$\mathrm{W}$ ith drug pipelines running dry and a slew of blockbuster medicines about to lose patent protection, the voices arguing that the traditional drugdevelopment process is too expensive and inefficient to survive are getting louder.

Employing thousands of in-house scientists to develop drug candidates from scratch has turned into a billion-dollar gamble that simply isn't delivering enough profitable products to market. Bernard Munos, founder of the InnoThink pharmaceutical policy research group in Indianapolis, Indiana, is not alone in believing that the next three years "will probably see an implosion of the old model" of drug discovery.

So what comes next? Cutbacks, certainly: witness Pfizer's dramatic announcement early last month that it will soon close its research site at Sandwich, UK, and slice roughly US $\$ 1.5$ billion from its proposed 2012 research and development spend (see Nature 470, 154; 2011). But beyond that, perhaps, a rethink of the old divisions of labour is needed.

Canny drug-makers are listening to those who propose that they should increasingly outsource early-stage drug development, including phase I safety trials, to academia or to small, specialist companies. This would leave pharmaceutical companies to focus on their strengths: running large clinical trials and marketing medicines.

One such model was the focus of a meeting in Toronto, Canada, on 16 February, involving some 40 leading lights from industry, academia and funding agen-

cies. The meeting was co-convened by Chas Bountra, head of the Structural Genomics Consortium at the University of Oxford, UK, who argues that a key problem with the current system is that companies tend to work in parallel, identifying similar or identical target molecules while remaining unaware that the compounds may have already been tested and discarded by rivals. "What we're trying to do is reduce that duplication," he says.

His scheme adopts the highly collaborative

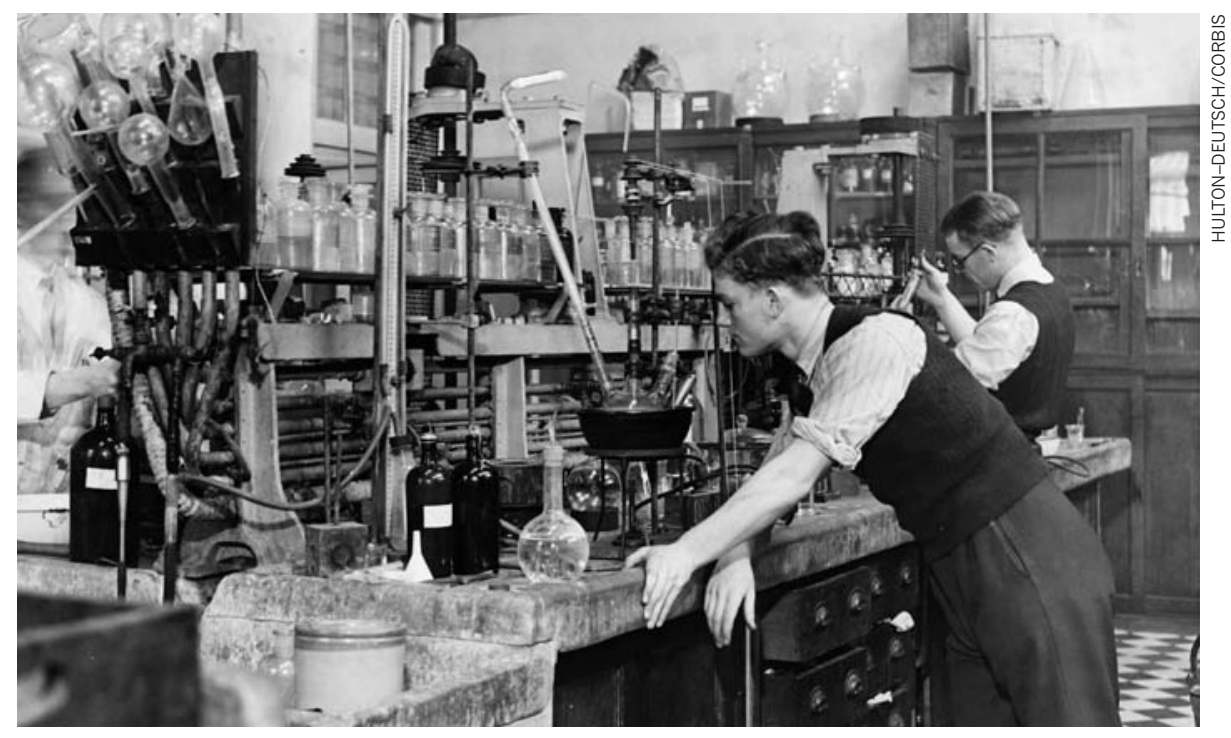

The kit may have improved, but the in-house drug discovery model has changed relatively little.

approach pioneered by those working on cures for neglected diseases, in which intellectual property (IP) restrictions are lifted. Companies would begin to compete only after early clinical trials had shown a drug to be safe and potentially effective. Up to that point, all data on prospective drug candidates would be published openly. This would allow targets to be validated much more quickly, says Bountra, potentially giving enormous savings in cost. It would also prevent companies "exposing patients to molecules that other organizations already know are going to be ineffective".

The model would rely heavily on academic scientists supported by a global initiative costing about $\$ 325$ million a year, with half coming from the pharmaceutical industry and half from public and charitable sources. Successful drug candidates would be made available for the initiative's commercial sponsors to buy and bring to market.

Industry already believes that this is a fine solution for programmes in areas without major commercial interest, such as neglected diseases, says Stephen Friend, an organizer of the meeting and president of non-profit research organization Sage Bionetworks, based

\section{$\rightarrow$ NATURE.COM}

For a longer interview with Patrick Vallance, see go.nature.com/beg9zf in Seattle, Washington. The key difference in the Toronto proposal is that it may also be a "viable way to improve return on investment in commercially important areas", he says.

Bountra is confident that within the next two months he will complete negotiations to sign up two industry partners, two public funding partners and two academic partners. The response at the meeting, to which all the large drug companies sent representatives, was very positive from all involved, say attendees. "The more we discussed it, the more convinced we were that this is the only way forward," says Bountra. A follow-up meeting in San Francisco in April will flesh out the plans.

Meanwhile, government funders of research are trying out similar initiatives. The UK Medical Research Council has established the Developmental Pathway Funding Scheme to support the development of basic science into drugs and medical devices. And Francis Collins, head of the US National Institutes of Health, is proposing a National Center for Advancing Translational Sciences to push more basic science towards the medical market (see page 15).

Ted Bianco, director of technology transfer for the Wellcome Trust, a UK biomedical research funder, agrees that shifting early-stage drug discovery work to academia could fix 
some of pharma's problems. The trust's Seeding Drug Discovery initiative already funds researchers to optimize drug candidates and take them through to clinical trials. But Bianco points out that commercial partners in Bountra's initiative would expect to see a financial return: "The dilemma is that heavy investment is required, and it has to be carried by somebody's money."

Bountra's IP-free model could also deprive collaborating universities of the opportunity to profit from spin-out companies, says Melanie Lee, chief executive of Syntaxin, a biotech company based in Oxford, UK, who attended the Toronto meeting. Bountra says he doubts that will discourage academics, who get into drug discovery to develop medicines, not to acquire intellectual property.

But Patrick Vallance, senior vice-president for medicines development and discovery at London-based drug-makers GlaxoSmithKline (GSK), also believes that IP will be the most contentious part of Bountra's model. "I'm completely on board with the idea you don't really know if you're on track until you've done an experiment in the clinic, and that you should publish that early," he says. But "it's much more complex to determine where you need to secure the IP along that chain, and I think it will differ from molecule to molecule".

Nevertheless, his company is experimenting with open innovation, having last year put more than 13,000 potential antimalarial drug structures into the public domain to encourage academics to identify promising leads. "One of the reasons I want to push that model very hard is that if it works in malaria - and we've yet to see what the uptake from academics and others is - I don't see how you could do anything but pursue it in other areas," says Vallance.

Vallance notes that industry is also developing new models of academic collaboration. GSK announced this month that it will collaborate with Mark Pepys, head of medicine at the Royal Free and University College Medical School in London, to develop a candidate drug for amyloidosis, a protein disorder. The idea, says Vallance, is not just to buy up promising molecules, but to form long-term partnerships that last all the way through drug development.

All these models put academic researchers at the heart of drug discovery. But they will fail unless more money flows from governments, charities and industry into academic labs, says Cathy Tralau-Stewart, who heads Imperial College London's drug discovery research unit. "Academic drug discovery is growing and is becoming much more important," she says, "but if we don't solve the funding issues, then the pharma companies will not have a pipeline of innovative drugs in ten years' time."

\section{Budget woes sink marine archive}

\section{Oceanographic library could be a casualty of California's \$25-billion deficit.}

\section{BY ERIKA CHECK HAYDEN}

$\mathrm{T}$ The fiscal crisis at the University of California looks set to engulf the world's largest collection of research materials focused on marine sciences.

On 11 February, Brian Schottlaender, librarian at the University of California, San Diego (UCSD), proposed closing the Scripps Institution of Oceanography Library, along with four other libraries affiliated with UCSD, including the Medical Center Library and the Science \& Engineering Library.

Schottlaender had been asked to cut US\$6 million out of his \$25-million budget as part of a $\$ 500$-million reduction for the entire University of California system. Newly elected state governor Jerry Brown, who faces a \$25-billion state deficit, announced the reduction in January. The Scripps library closure is the highest-profile casualty of the cuts so far, but it is unlikely to be the last.

The library includes some 227,000 books and 700 print periodicals along with an extensive archive that charts the history of oceanography, including documents from the $1872-76$ voyage of HMS Challenger - a landmark global oceanographic expedition. News of the planned closure has elicited a storm of protest. "Closing the Scripps library is almost unthinkable," says Walter Munk, a pioneering oceanographer who spent his entire professional career at the Scripps institution. "The Scripps library is a unique asset to the community of oceanographers everywhere." A group of Scripps graduate students has organized a petition opposing the closure.

Select collections and services from the library could be moved to a larger library on UCSD's main campus as early as this summer, according to Schottlaender. And
Peter Brueggeman, director of the Scripps library, notes that about half of the library's collection has been digitized through a partnership with Google. But, he says, "the reality is that many research-oriented library resources are not yet digitized, are not freely available or are not affordable at this time".

Schottlaender points out that, before this year's proposed cut, his budget had already been reduced by $16 \%$ since 2008 and that the Scripps library, with 34,000 visitors last year, is not as heavily used as other libraries on campus. "My hands are more are less tied. Everything is getting cut everywhere," Schottlaender says.

Other libraries are feeling the pinch too (see 'Shrinking pool'). At the University of California, San Francisco, librarian Karen Butter says that she doesn't have the budget to subscribe to some databases that researchers want, such as BIOBASE which contains products such as the Human Gene Mutation Database, an archive of mutations associated with disease. She adds that the university is negotiating with publishers to lower the cost of online access to individual journals, because packages of journals are no longer affordable. On 1 January, the University of California library system cancelled its site licence to the Informa Healthcare journals - the first time the university has cancelled a subscription to a 'bundle' of journals.

At the University of California, Santa Cruz, hundreds of undergraduate and graduate students occupied its science and engineering library in 2009 and 2010 to protest over cuts in library hours. In May, the students voted to institute a $\$ 6.50$ library fee per student per quarter to pay to keep the library open. But the fee ends in 2013. At that point, says university librarian Virginia Steele, "we're facing a really difficult dilemma". . 